\title{
Systemizing Virtual \\ Learning and \\ Technologies by \\ Managing Organizational \\ Competency and Talents
}

Advances in Developing Human

Resources

12(6) 715-727

(c) 2010 SAGE Publications

Reprints and permission: http://www.

sagepub.com/journalsPermissions.nav DOI: I0.1 I77/|5234223।0394795 http://adhr.sagepub.com

(SAGE

\section{Seung Won Yoon' and Doo Hun Lim²}

\begin{abstract}
The article presents promising components and practices of virtual learning and technologies and discusses how systemization can be made through managing organizational competency and talents. The main goal is to suggest how technologies should be incorporated within an organization to improve the effectiveness of employees' learning, performance, and development. For technology implementation and adoption, we also introduce models for examining organizational maturity levels and integrating technologies. We argue that virtual learning and technologies are fundamentally pressing HRD roles to change from experts of learning and development to work solution partners leading and supporting the creation of a smart organization.
\end{abstract}

\section{Keywords}

virtual learning, technology, competency, talent management, VHRD

\section{Introduction}

This special issue on virtual Human Resource Development (VHRD) from the journal of Advances in Developing Human Resources attempts to establish theoretical and research frameworks to positively impact emerging practices of workplace learning and performance in virtual environments. Other topics included in this issue, such as

\footnotetext{
'Western Illinois University, Macomb, IL

${ }^{2}$ University of Oklahoma, Norman, OK
}

Author Note: This article was subjected to a two-tier, blind review process that did not involve any of the contributing authors who are currently members of the editorial board.

\section{Corresponding Author:}

Seung Won Yoon, Instructional Design and Technology, Horrabin Hall 47, Western Illinois University, Macomb, IL 6I455

Email: s-yoon@wiu.edu 
the historical look at VHRD and definitions offered for this construct, adult learning in virtual environments, popular Web 2.0 tools, and assessments will deepen our discussion of conceptualizing and implementing virtual learning and technologies for managing organizational competency and talents.

Those who have lived through the emergence, promises, and turbulence of the Internet will probably take the stance that the impact of Information or Instructional Technology (IT) is always contingent upon many context-specific factors. Scholars cautiously (and rightfully) conclude that an old technology persists with introduction of a new technology to make decisions of selection and phase-out difficult (Reiser \& Dempsey, 2007). Any argument advocating for the positive promises of technology misses the critical importance of (a) placing goals and strategies before technology, (b) continuously managing consequences, and (c) proactively involving key stakeholders for evolutionary paths (Yoon \& Ardichvili, 2010). Wang and Wang (2009) pointed out that technology adoption is a complex social phenomenon that is dependent on complex relationships among psychological, organizational, and systems variables (i.e., members' confidence, perceived usefulness and ease of use, pressure from peers and the organization, and the quality of information, system, and service).

In this article, we present promising components and practices of virtual learning and technologies, discuss their relevance to VHRD, and explore how concepts and ideas from organizational competency, talents, and technology adoption can be used to prioritize and systemize VHRD practices. The main goal is to suggest how technologies should be conceptualized and implemented within an organization to improve the effectiveness of employees' learning, performance, and development. Although topics, such as talent management and HR planning can be seen as the domain of human resource management (HRM), HR and closely related fields (e.g., HRD, HRM, organizational development, human performance technology, and instructional technology) are converging to become strategic partners for leading organizational competitiveness through human learning and performance (Cho \& Yoon, 2010; Ruona \& Gibson, 2004). Components and practices of virtual learning and technologies were drawn from several related topics, in particular, the learning and performance architecture (Rosenberg, 2006); strategic blended learning (Yoon \& Lim, 2007); a holistic view of informal learning (Marsick, 2009); and technologies for HRD (Benson, Johnson, \& Kuchinke, 2002; Yoon, 2008).

We believe that virtual learning and technologies are fundamentally pressing the role of HRD to change from experts of learning and development to work solution partners leading the creation of a smart organization. Rosenberg (2006) defined a smart enterprise as "a high-performing organization that allows knowledge and capabilities, enabled by technology, to grow and flow freely across departmental, geographical, or hierarchical boundaries, where it is shared and made actionable for the use and benefit of employees, partners, customers, and suppliers" (italics added, p. 39). 


\section{Defining Virtual Learning and Technologies}

Two discrete meanings are commonly used for virtual. First is to describe the hypothetical or imaginary existence through the mind or indirect experiences. The other, which is relevant to our discussion, is the simulated reality occurring in a computer or computer networks. As for learning, we view learning as "a basic human activity that takes place everywhere and every day. . . the people who do the work conscientiously are constantly learning" (italics original, Rosenberg, 2006, p. 3). Although our primary focus is on virtual learning, we maintain that learning should be purposefully and strategically blended (Rosenberg, 2006; Yoon \& Lim, 2007).

Rosenberg (2006) aptly pointed out that the common use of blended learning as the integration of classroom and technology-based learning is too limiting because it defaults to an instructional approach that misses other approaches, which can be more appropriate (e.g., informal guides or personal networks). He suggested that "an expanded view of blended learning includes the combination of (formal) training and (informal) nontraining approaches . . in ways that improve the effectiveness and efficiency of learning" (pp. 83-84). Yoon and Lim (2007) similarly defined strategic blending as a purposeful mix of delivery media, particularly face-to-face (for its supremacy in clarification and clear introduction) and four major forms of Web technologies: (a) web/ computer-based training, (b) web/ performance support system and knowledge management, (c) web/asynchronous tools, and (d) web/synchronous communication and collaboration tools to improve learning and performance solutions, which are derived from the goals and needs of an organization.

Defining and studying technology for HRD is important because of rapid changes in workplace learning and performance (WLP) driven by technologies. In 2002, Benson, Johnson, and Kuchinke presented a comprehensive conceptual framework of technology for HRD in the digital workplace. They listed major IT tools (e.g., enterprise resource planning systems, learning management systems, performance support systems, instant messengers, email, and so on) around three core domains of HRD: Learning, performance enhancement, and organizational development and change. Yoon (2008) further developed their work and proposed studying technologies in the domains of learning, performance, and work-affecting life because the domain of organizational development and change overlap with domains of learning and performance, whereas new life practices of searching, posting, and sharing information on the Internet drastically affect WLP. He also suggested that technology should be understood as a systematic treatment of art and craft as well as the application of knowledge in a particular domain using technical processes, methods, and scientific knowledge. Taken together, we emphasize that (a) virtual learning and technologies highlight the importance of utilizing computer and network technologies to enhance learning, and (b) context, methodical and systematic processes, creativity, and the effectiveness and efficiency of solutions matter much more than semantic distinctions between forms of delivery technologies. 


\section{Promising Components: Learning and Performance Architecture}

Rosenberg (2006) suggested that a smart enterprise, a high-performing organization where knowledge and capabilities grow and flow by technology, is the result of four major forces: (a) leadership that emphasizes learning and performance, (b) change management, (c) performance-centric environments, and (d) the learning and performance architecture (LPA). It is the LPA that helps us identify core components and practices of virtual learning and technologies. His concept of a smart enterprise is similar to that of a learning organization, a term that is more familiar to many HRD professionals. A learning organization is an ideal structure and culture that embeds learning into work routines (Tsoukas \& Mylonopoulos, 2004). It acquires, processes, and disseminates knowledge about markets, products, technologies, and business processes based on information, experiences, and experimentations (Jensen, 2005). The learning organization literature has also established essential system characteristics and employee behaviors: Continuous learning, inquiry/dialogue, team learning, empowerment, system connection, embedded systems, and leadership (Yang, Watkins, \& Marsick, 2004).

However, descriptions of the system connection and the embedded system, two components that define the use of technologies in the learning organization literature limit the types and uses of technologies to skills databases and information systems. The overall status of HRD research on technology between 2000 and 2006 also indicates that the dominant majority of studies (61\%) took place within formal instructional settings (Githens, Dirani, Gitonga, \& Teng, 2008). To leverage what network technologies truly offer for WLP, a more strategic and integrative framework that aligns major IT tools (from domains of learning, performance, and work-affecting life (See Yoon, 2008) with core practices of WLP, which capture both formal and informal learning and knowledge sharing, is necessary.

The LPA framework suggests that organizations should implement and integrate formal learning (onsite and online training) with informal learning (knowledge management (KM), performance support systems, and mentoring/coaching) making the best use of digital technologies. Two very far-reaching notions are that (a) KM is a combination of information repositories, (virtual) communities and networks, and experts/expertise, and (b) e-learning is more than e-training and must include online training, KM, and performance support systems. Such conceptualization of informal learning and technologies is in agreement with Marsick's (2009) observation that informal learning usually happens in the pursuit of a mix of individual and organizationally set goals, and research will be more fruitful if studied in the context of KM within organizations.

Identifying the focus of learning (e.g., acquiring knowledge on newly established procedures/processes or collaboratively determining problem solutions) and learningcontributing technologies (e.g., information retrieval, expert identification, virtual conferencing, or real-time collaborative editing, etc.) is vital if we admit that the context 
of business learning is losing the ground for learning away from work (i.e., formal learning), and instead, favors access to knowledge, data, and others' expertise at the moment of need. Moving from onsite training to online training, and then to KM or collaboration, and then to performance support systems implies less disruption of work to learn. Rosenberg (2006) stresses that these components are not organized as singular, isolated functions but as part of a broad-based LPA. The next section illustrates why a strategic and integrative system is imperative.

\section{Promising Practices: Knowledge- over Training-centric Approaches}

When performance problems arise or new initiatives are rolled out, too often training or another learning solution is proposed. For example, when both authors separately taught graduate-level courses in human performance technology, most learners shared the "default" approach to suggesting onsite or online training solutions to diverse issues, such as work-order backlogging, service quality improvement, leadership development for mid-level managers, teachers' professional development, student enrollment at universities, and developing dealers' competence. With an increased capacity to reach knowledge, data, and others' expertise using virtual technologies, knowledgecentric approaches to a hypothetical topic of talent management will look more like Figure 1. Jensen's (2005) definition of knowledge as information extracted or organized from data applied for a productive purpose helps to see how a knowledge-centric view purposefully integrates training with informal learning and knowledge sharing as a part of comprehensive WLP solutions focusing on the generation of useful knowledge.

Figure 1 also shows, for a hypothetical goal of talent management, how popular virtual technologies, especially Web tools and services, such as blogging, wikis, real simple syndication or rich site summary (RSS), social bookmarking tools (Beldarrain, 2006), virtual worlds (O’Conner \& Menaker, 2008), vCoP (Ardichvili, 2008), KM (Gourlay, 2001), and performance support systems (Gery, 2002) can be purposefully used to support major learning activities and processes within a strategically blended learning environment (Yoon \& Lim, 2007). We cannot assume that employees will voluntarily utilize various forms of learning opportunities and technologies. At the same time, training or learning departments are pressured to make selective choices in technologies and be more responsive. Typical training and learning departments alone may not have needed resources, knowledge, and the budget to design and lead the LPA framework without working closely with leadership and business units. Bold-faced items on the figure also indicate that more than one popular Web tool exists, thus in adopting technologies, organizations must examine the administrative demands, technological affordances, and the potential impact of selected technologies to linked components.

Marsick (2009) pointed out that informal learning is always contrasted with formal learning in the literature, but in reality, both interact frequently and in important ways. 


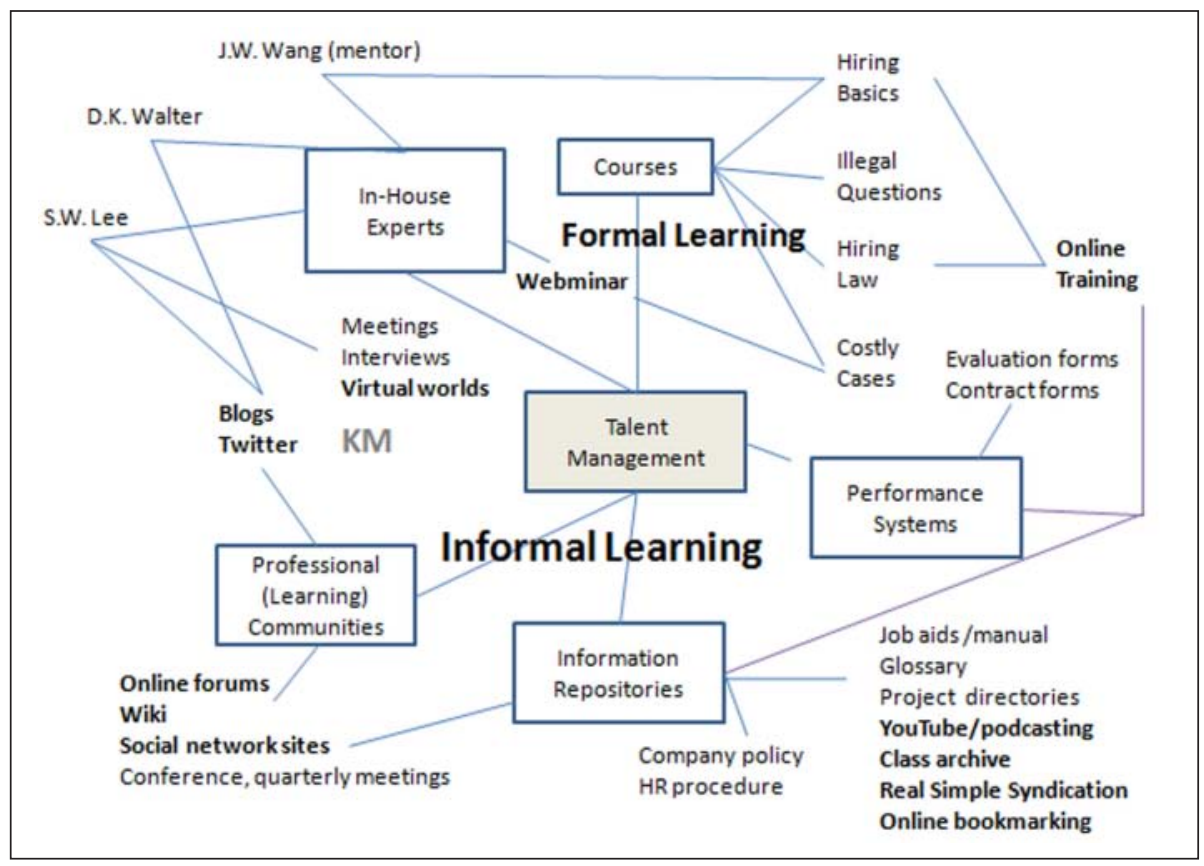

Figure I. Knowledge-centric components and practices of workplace learning and performance

Davenport (2005) drew attention to the idea that types of knowledge work differ based on the level of work interdependence and the complexity (routine vs. interpretive work) and suggested that technologies be selected accordingly. For instance, transaction workers whose responsibilities are largely procedure-based will benefit more from the use of information repositories to perform routine tasks than with tools for collaboration, while virtual meetings can be critical for geographically dispersed cross functional teams to make creative decisions.

\section{Virtual Learning and Technologies and VHRD}

Related to the theme of this issue, our preceding discussion of the LPA framework and technology-enabled knowledge-centric approaches to WLP supports Bennett's (2009) proposed definition of VHRD as "a media rich and culturally relevant web environment that strategically improves expertise, performance, innovation, and communitybuilding through formal and informal learning" (p. 365). Bennett's definition is akin to the concept of blended learning proposed by Rosenberg (2006) and Yoon and Lim (2007) highlighting the importance of network technologies. What we add to her proposed definition are that (a) VHRD should not be the sole responsibility of this 
profession, whether it is called HRD, WLP, training, training development, workforce development, or performance technology (Galagan, 2003), (b) informal learning consists of multiple forms (e.g., KM, mentoring/coaching, and performance support systems) and its presence will continuously increase due to the increasing needs for less disruption of work, (c) informal learning needs to be part of integrative learning and performance solutions that include formal learning, and (d) web technologies can be purposefully used for multiple formal or informal learning as Figure 1 illustrates. A powerful new technology can radically change core assets and activities of any industry, thus technologies that massive audience use or target customers adopt must be scrutinized by organizations (McGahan, 2004).

When powerful and promising tools are many (e.g., virtual worlds, blogging, and social networking, and so on), determining positioning to lead or follow the use of emerging technologies can be difficult. An organization will need to make tough decisions at times between double-loop and triple-loop learning. Jensen (2005) explains that the latter is similar to taking the leading position to explore unchartered paths and tap new possibilities despite uncertainties and higher chances of failure, whereas the former questions existing strategies and assumptions to change norms. If existing development or evaluation practices of onsite or online training are applied to implementing new virtual learning and technologies with few changes, it is equivalent to single-loop learning, which maintains the status quo, thus it will not simply work. Given the nascent status of theoretical and conceptual frameworks for guiding or evaluating VHRD, starting dialogues on which formal and informal learning options are critical and which technologies will best enhance expertise, performance, and innovation can be the first step. Examining the organization's competency and talent management systems as well as its maturity (Persse, 2001) and technology adoption plan (Kopcha, 2008) can further guide and systemize desirable VHRD practices.

\section{Organizational Competency and VHRD}

The goals of introducing competency in the workplace are to standardize the knowledge and skills of employees for developmental purposes (Valkeavaara, 1998); to align HR planning and development activities with the organization's strategic direction through effective recruiting, training, coaching, and rewarding (Moinat, 2003); and to provide more direct information related to business goals and strategies (Shippmann et al., 2000). To determine what types of learning, informal learning in particular, and technologies are most important for the organization, HRD can gather which technology skills and practices employees value the most using an online survey or by interviewing model performers (Rossett, 2009).

In earlier days, competency was viewed broadly as psychological or behavioral attributes associated with vocational success (McClelland, 1973). Later, it shifted to a more specific view of knowledge, skills, and abilities (Mirable, 1997), a set of behaviors to be competent in the workplace (Woodruffe, 1993) and those determining factors for acting successfully in a job or task situations (Lucia \& Lespinger, 1999). 
Competency can also contain multilevel organizational capabilities at the team and the organizational level (Godbout, 2000).

The importance of competency has been raised to the strategic level as organizations must compete with intellectual assets and capabilities identifiable by others (Prahalad \& Hamel, 1990). A core competency is a cluster of extraordinary abilities and specific strengths of organizational members as a whole (Hayton \& Kelley, 2006), and it is the main driver of delivering value to the customers (Godbout, 2000). Core competencies are therefore the primary means that enable organizations to respond to their environments. Internally, they also provide operational effectiveness, cultural integration, organizational alignment, and directions for organizational changes (Daniels, Erickson, \& Dalik, 2001).

A competency model is a collection of core competencies for successful job performance (Dubois \& Rothwell, 2004). In a competency model, the effective and desired characteristics of behaviors are described in broader terms. For instance, traditionally, based on job analyses, experts in most organizations are engaged in actions of performing work routines, troubleshooting, and helping others with occasional responsibilities of documenting work or teaching. Within virtual learning and technology environments, however, where knowledge is frequently tacit or changes fast or the nature of work is new and untested, experts are extremely valuable with validating ideas, locating what is important, and pointing people to additional and reliable knowledge sources (Rosenberg, 2006). Figure 1 shows that competencies in areas, such as teaching or facilitating e-learning (Aragon \& Johnson, 2002), virtual mentoring (Bierema $\&$ Hill, 2005), making experience-based knowledge available through online publishing, information repository, or virtual worlds are vital in VHRD. It also signifies that an organization's selection, utilization, and integration of various technologies are critical for the success of VHRD. Although not specified in that figure, competency in digital literacy and citizenship in terms of netiquette, web safety and security, and individual rights and responsibilities would be increasingly important (Ribble, Bailey, \& Ross, 2004).

\section{Talent Management and VHRD}

If managing organizational competency helps prioritize types of learning and technologies, talent management is to create a system to draw, develop, and retain the talents. The media-rich and culturally diverse environment of VHRD implies that an HR system that swiftly and effectively locates, places, enhances, and rewards experts and expertise in environments, such as information systems (Rosenberg, 2006) and vCoP (Ardichvilli, 2008) is important. Talent management needs to be a part of HRD practices and involves recruiting, selection, development, and career and succession management (Garrow \& Hirsh, 2008). It is also a set of processes designed to ensure an adequate flow of employees into jobs throughout the organization (Schweyer, 2004). Talent management contributes to building proactive learning and performance culture, engagement, capability, and capacity through integrated talent acquisition, 
development, and deployment processes (ASTD, 2009). Its primary focus is on increasing the capacity of high performing and high potential talents committed to the organization (Collings \& Mellahi, 2009).

Forward-looking organizations are constantly changing their strategies for building the workforce. Key characteristics of growing organizations include cultivating existing talent rather than recruiting new people, improving employee satisfaction through personal career plans and development opportunities, planning ahead for succession of mission critical positions, and actively acting on performance management (Cappelli, 2008). Technologies, such as system analytics, database queries, and user tagging and rating can facilitate these tasks by locating talents based on credentials, interests, or content ownership, filtering active contributors to $\mathrm{vCoP}$ or KM systems, or examining the concentration of interactions and information flow within networks. Organizations need to create a unified system that aligns organizational learning with knowledge and performance management (Schweyer, 2004; Yoon \& Ardichvili, 2010).

\section{Organizational Maturity and Planning for VHRD}

Examining the level of organizational maturity and applying the matrix of technology integration (Kopcha, 2008) can further guide the planning and implementation of VHRD. For organizational maturity, the capability maturity model (CMM) is widely used by many organizational researchers (Persse, 2001). The structure of the CMM comprises maturity levels, key process areas, goals (of key process areas), common features, and key practices (contributing to the implementation of the key process areas). The CMM is composed of five developmental stages: Initial, Repeatable, Defined, Managed (Predictable), and Optimizing. First, the Initial level is characterized as having difficulties in retaining talented individuals and organizational processes are that are ad-hoc and chaotic.

At the Repeatable level, organizational basic processes are established and the task practices focus on activities at the unit level. At the Defined level, most processes are documented, standardized, and integrated so that the organization shapes a systemwide infrastructure to fully utilize the capability of the workforce. During the Managed (Predictable) level, organizations start exploiting the capability of their workforce competencies and manage their performance quantitatively. Organizations planning to adopt and increase the use of virtual technologies can first identify individuals and work units to support selected LPA components (during the initial and the repeatable stage), but to be adopted and systemized organization-wide, gradual conversion to later stages with defined goals and timeline targets will be needed.

VHRD challenges organizations to simultaneously manage dimensions of mechanics, work environments, culture, and core competencies along differing stages of technology integration: Initial set-up, employee preparation, performance focus, and system-wide communities. Kopcha (2008) developed a matrix for teachers' integration of technologies in order to overcome past failures of individual- and skills-focused approaches. We substitute employees and core competencies for teachers and curricular 
from that model. In this framework, experts and model performers as mentors shift their roles based on the stage of technology integration. During earlier stages of initial set-up and employee preparation, they focus on helping inexperienced users with troubleshooting, basic training, and on-boarding, and gradually, their emphasis moves onto modeling, sharing, leading small communities of practice, enlisting support from the leadership, and forming more peer mentors.

\section{VHRD: Advancing Toward What HRD Should Be}

At the beginning, we argued that virtual learning and technologies are fundamentally pressing HRD roles to change from experts of learning and development to work solution partners leading and supporting the creation of a smart organization (enterprise). Our discussion of knowledge-centric approaches compelled purposeful and strategic uses of virtual technologies to best support various forms of WLP, which observes the growing importance of informal learning and web tools. We also discussed how prioritizing and systemizing technologies can be guided from the analysis of organizational competency and talents, maturity, and technology adoption plans. The blended learning environment and knowledge-centric approaches provided conceptual backgrounds for what would be further expected of WLP and VHRD. In VHRD, because formal onsite or real-time virtual synchronous learning will be implemented to present information and knowledge at the beginning or midway for best organization, clarification, and collaborative problem-solving, (a) the traditional HR professionals' expert roles in administering, promoting, and assessing formal learning will persist, but for informal learning, (b) HR professionals will need to strengthen their skills in planning, aligning, leading, and supporting self-initiated learning and information sharing through technologies. We find that qualitative research should help identify positive and negative practices as well as their patterns and themes to be later used in quantitative or mixed-method studies to validate or measure promising VHRD concepts.

\section{Declaration of Conflicting Interests}

The author(s) declared no potential conflicts of interest with respect to the authorship and/or publication of this article.

\section{Funding}

The author(s) received no financial support for the research and/or authorship of this article.

\section{References}

Aragon, S. R., \& Johnson, S. D. (2002). Emerging roles and competencies for training in e-learning environments. Advances in Developing Human Resources, 4, 424-439.

Ardichvili, A. (2008). Learning and knowledge sharing in virtual communities of practice: Motivators, barriers, and enablers. Advances in Developing Human Resources, 10, 541-554.

ASTD. (2009). The new face of talent management (ASTD whitepaper). Alexandria, VA: ASTD Press. 
Beldarrain, Y. (2006). Distance education trends: Integrating new technologies to foster student interaction and collaboration, Distance Education, 27, 139-153.

Bennett, E. E. (2009). The intersection of knowledge management, culture, and intranets. Advances in Developing Human Resources, 11, 362-374.

Benson, A., Johnson, S., \& Kuchinke, P. (2002). The use of technology in the digital workplace: A framework for human resource development. Advances in Developing Human Resources, 4, 392-404.

Bierema, L. L, \& Hill, J. R. (2005). Virtual mentoring and HRD. Advances in Developing Human Resources, 7, 556-568.

Cappelli, P. (2008). Talent on demand: Managing talent in an age of uncertainty. Boston, MA: Harvard Business School Press.

Cho, Y., \& Yoon, S. W. (2010). Theory development and convergence of human resource fields: Implications for human performance technology. Performance Improvement Quarterly, 23, $39-56$.

Collings, D. G., \& Mellahi, K. (2009). Strategic talent management: A review and research agenda, Human Resource Management Review, 19, 304-313.

Daniels, D. R., Erickson, M. L., \& Dalik, A. (2001). Here to stay - Taking competencies to the next level. WorkatWork Journal, 10(1), 70-77.

Davenport, T. (2005). Thinking for a living: How to get better performances and results from knowledge workers, Boston, MA: Harvard Business School Press.

Dubois, D. D., \& Rothwell, W. J. (2004). Competency-based human resource management. Palo Alto, CA: Davies-Black Publishing.

Galagan, P. (2003, December). The future of the profession formerly known as training. $T+D$, 57(12), 26-38

Garrow, V., \& Hirsh, W. (2008). Talent management: Issues of focus and fit. Public Personnel Management, 37, 389-402.

Gery, G. (2002). Achieving performance and learning through performance-centered systems. Advances in Developing Human Resources, 4, 464-478.

Githens, R. P., Dirani, K., Gitonga, J., \& Teng, Ya-Ting. (2008). Technology-based research in HRD publications: An analysis of content and metaperspectives from 2000 to 2006. Human Resource Development Quarterly, 19, 191-215.

Godbout, A. J. (2000). Managing core competencies: The impact of knowledge management on human resources practices in leading-edge organizations. Knowledge and Process, 7(2), 76-86.

Gourlay, S. N. (2001). Knowledge management and HRD. Human Resource Development International, 4(1), 27-46.

Hayton, J. C., \& Kelley, D. J. (2006). A competency-based framework for promoting corporate entrepreneurship. Human Resource Management, 45, 407-427.

Jensen, P. E. (2005). A contextual theory of learning and the learning organization. Knowledge and Process Management, 12(1), 53-64.

Kopcha, T. J. (2008). A systems-based approach to technology integration using mentoring and communities of practice. Educational Technology Research and Development, 58, 175-190. 
Lucia, A. D., \& Lepsinger, R. (1999). The art and science of competency models: Pinpointing critical success factors in an organization. San Francisco, CA: Jossey-Bass/Pfeiffer.

Marsick, V. (2009). Toward a unifying framework to support informal learning theory, research, and practice. Journal of Workplace Learning, 21, 265-275.

McClelland, D. (1973). Testing for competence rather than intelligence. American Psychologist, 28, 1-14.

McGahan, A. M. (2004). How industries evolve. Boston, MA: Harvard Business School Press.

Mirable, R. (1997, August). Everything you wanted to know about competency modeling. $T+D$, 73-77.

Moinat, S. (2003). The basics of competency modeling. St. Paul, MN: Full View Solutions.

O'Connor, D. L., \& Menaker, E. (2008). Can massively multiplayer online gaming environments support team learning? Performance Improvement Quarterly, 22(2), 23-42.

Persse, J. R. (2001). Implementing the capability maturity model. New York, NY: John Wiley.

Prahalad, C. K., \& Hamel, G. (1990). The core competence of the corporation. Harvard Business Review, 68(3), 79-91.

Reiser, R. A. \& Dempsey, J. V. (2007). Trends and issues in instructional design and technology (2nd ed). Upper Saddle River, NJ: Merrill/Prentice Hall.

Ribble, M., Bailey, G. D., \& Ross, T. W. (2004). Digital citizenship: Addressing appropriate technology behavior. Learning \& Leading with Technology, 32(1), 6-12.

Rosenberg, M. (2006). Beyond E-Learning: Approaches and technologies to enhance organizational knowledge, learning, and performance. New York, NY: Pfeiffer.

Rossett, A. (2009). First things fast: A handbook for performance analysis (2nd ed.). San Francisco, CA: Pfeiffer.

Ruona, W. E. A., \& Gibson, S. K. (2004). The making of twenty-first-century HR: An analysis of the convergence of HRM, HRD, and OD. Human Resource Management, 43, 49-66.

Schweyer, A. (2004). Talent management systems: Best practices in technology solutions for recruitment, retention and workforce planning. New York, NY: John Wiley.

Shippmann, J. S., Ash, R. A., Battista, M., Carr, L., Eyde, L. D., \& Hesketh, B. (2000). The practice of competency modeling. Personnel Psychology, 53, 703-740.

Tsoukas, H., \& Mylonopoulos, N. (2004). Introduction: Knowledge construction and creations in organizations. British Journal of Management, 15(S1), S1-S8.

Valkeavaara, T. (1998). Human resource development roles and competencies in five European countries. International Journal of Training and Development, 2, 171-189.

Wang, W., \& Wang, C. (2009). An empirical study of instructor adoption of web-based learning systems. Computers \& Education, 53, 761-774.

Woodruffe, C. (1993). What is meant by a competency? Leadership \& Organization Development Journal, 14(1), 29-36.

Yang, B., Watkins, K. E., \& Marsick, V. J. (2004). The construct of the learning organization: Dimensions, measurement, and validation. Human Resource Development Quarterly, 15(1), 31-55.

Yoon, S. W. (2008). Technologies for learning and performance. In A. Rozanski, K. P. Kuchinke, K. P., \& E. Boyar (Eds.), Human resource development theory and practice (pp. 245-261). Lublin, Poland: Lublin Technical University. 
Yoon, S. W., \& Ardichvili, A. (2010). Applying Vygotskian thought, situated learning theory, and holistic learning and performance architecture in the design of integrated knowledge management systems. International Journal of Knowledge Management, 6(4), 47-59.

Yoon, S. W., \& Lim, D. H. (2007). Strategic blending: A conceptual framework to improve learning and performance. International Journal on E-Learning, 6, 475-489.

\section{Bios}

Seung Won Yoon is an associate professor in the Department of Instructional Design and Technology at Western Illinois University. His $\mathrm{PhD}$ is in human resource development from the University of Illinois. His research focuses on applying theories of learning, instruction, and information design to e-learning, blended learning, and human performance technology and examining impacts quantitatively and qualitatively.

Doo Hun Lim (PhD, University of Illinois at Urbana-Champaign) teaches at the University of Oklahoma as an associate professor in the areas of program planning, technologies for learning and performance improvement, and cross-cultural issues in HRD. His research interest focuses on training transfer, blended learning, and cross-cultural studies in workplace issues including work ethic, OD, KM, work/family relationships, and instrument validation. 